\title{
REASONS FOR CHOICE OF PLACE OF DELIVERY AMONG WOMEN OF REPRODUCTIVE AGE IN A SEMI URBAN POPULATION IN NORTH CENTRAL NIGERIA
}

\author{
Shambe IH ${ }^{I^{*}}$, Pam VC $C^{1}$ Enokela $\mathrm{MA}^{1}$, Oyebode $\mathrm{TA}^{1}$, GyangMD ${ }^{1}$, Gyang BZ ${ }^{2}$, Envuladu EA. ${ }^{3}$ \\ Department of Obstetrics and Gynaecology ${ }^{1}$, Department of Family Medicine ${ }^{2}$ and Department of Community Health ${ }^{3}$, \\ University of Jos.
}

\author{
*Correspondence Author: Dr. I.H. Shambe Department of Obstetrics and Gynaecology, University of Jos, P.M.B 2084 Plateau \\ State Nigeria.E-mail: iornum@yahoo.com
}

Received date: March $08^{\text {th }}$, 2018, Accepted date: March $26^{\text {th }}, 2018$. Published date: April $20^{\text {th }}, 2018$

\begin{abstract}
Where women choose to deliver affects their access to skilled birth attendant and potentially determines the outcome of the pregnancy. This is an important factor against the backdrop of high maternal and neonatal mortality rates in Nigeria. The choice of place of delivery and factors that determine such choices are therefore pertinent considerations in the path to safe motherhood. To assess the factors that determine the choice of place of delivery by women of reproductive age, this cross sectional study was carried out between January to March 2015 in Vom , a semi urban area about 30km from Jos the capital of Plateau State among 2,640 (Two thousand six hundred and forty) women of reproductive age. The mother's safety was the major factor that influenced the choice of place of delivery by $1,927(73 \%)$ of the respondents, the cost of services was the next determinant in $633(24 \%)$ of the respondents while the attitude of the health care providers at hospitals was the least consideration in $79(3 \%)$ of the respondents for the choice of place of delivery. The most preferred place of delivery was hospitals (80\%) while home delivery and deliveries with Traditional Birth Attendants were favoured by $19 \%$ and $1 \%$ of the respondents respectively. The majority of the respondents (32\%) were between the ages of $40-44$ years while $22 \%$ were between 25-29years of age. The respondents were predominantly farmers of the Berom ethnic group (99\%) and $47 \%$ of them had completed primary level of education. The safety of pregnant mother was the major consideration that influenced the place of delivery among women of reproductive age in this population. Hospital delivery was the most favoured place of delivery.
\end{abstract}

Keywords: Reproductive age, delivery intentions, place of delivery.

\section{Introduction}

Maternal mortality in sub-Saharan Africa and Nigeria in particular is still unacceptably high. Maternal Mortality Ratio (MMR) in Nigeria was estimated to be 560 per 100,000 live births as at 2013. ${ }^{1}$ The maternal mortality ratio however vary from region to region. ${ }^{2,3}$ Many of the causes of maternal mortality however may be mitigated by having a skilled birth attendant at delivery. ${ }^{4}$ While antenatal attendance has shown a steady increase in Nigeria from 2008 to 2013, skilled birth attendance at delivery in the North
Central region where this study was done only showed a marginal increase from $42.7 \%$ to $46.5 \%$ and delivery in health facilities rose from $41 \%$ to $45.7 \%$ within the same time frame. ${ }^{5}$ Other studies have shown a high rate of home deliveries among pregnant women in Nigeria even when they may have benefited from antenatal care. ${ }^{6}$ This is of concern because globally delivery assistance has been shown to be crucial in reducing maternal mortality ratio yet many women in Nigeria deliver in places where they do not have access to a skilled birth attendant. $^{7}$ The imbalance in availability of 
health facilities between urban and rural areas may influence the choices pregnant women make as to where to deliver and factors such as the availability of hospitals near settlements, the cost of health care as well as the attitude of health care workers at such facilities are a few factors that may determine where women deliver. ${ }^{7}$

We therefore, sought to assess the factors that determine the choices women in the reproductive age in a semi urban community in Vom North Central Nigeria make about places they wished to deliver.

\section{Materials \& Methods}

This was a cross sectional study carried out in Vom district of Plateau state, Nigeria, an area predominantly populated by the Berom ethnic group. The Vom district comprises of 4 wards namely Vwang, Chugwi, Turu A and Turu B wards and has a population of 121,284 according to the 2006 census. The district is about 30 kilometres from Jos the capital of Plateau State and covers an area of 155 kilometers. It is served by a secondary Health facility, the Vom Christian Hospital which is a faith based facility and a few private health care facilities and primary health care clinics.

Advocacy visits were paid to the district Head, and the 4 village heads who gave permission for the study to be carried out. A minimum sample size of 2000 was calculated and proportionally allocated to the 4 wards based on the number of their households already determined by the 2006 population census in Vom. The total number of households were divided by allotted sample sizes in each of the 4 wards in the community to get the sampling interval of 5 .

A structured and pretested questionnaire was then administered to females aged between 15-49 in the households. The questionnaires were administered by midwifery students who were trained for the task.

Sample size Calculation Step 1:n1= Z1p (1-p)/e2

Where $\mathrm{n}=$ sample size

$\mathrm{Z}=$ level of confidence $(1.96$ or $95 \%)$

$\mathrm{P}=$ baseline level of indicators $(0.5$ or $50 \%)$

$\mathrm{e}=$ margin of error

Step 2: $\mathrm{n} 2=\mathrm{n} 1 /(1+[\mathrm{n} 1 /$ population $])$

Step 3: $\mathrm{n} 2=\mathrm{n} 2$ design effect

Step 4: $n 4=n 3 /$ response rate

The minimum calculated sample size for this study was 2000 however a total of 2800 questionnaires were administered but 160 were incompletely filled and were not analyzed. The properly filled questionnaires were 2640 and data was collected and analyzed using. IBM SPSS, $\mathrm{p}$ value was $<0.005$ for significance. The results were tabulated and analyzed using simple percentages. Descriptive statistics were analyzed while chi square was used to determine statistical significance between socio demographic characteristics and preferred places of delivery. A total of 2640 women completed the questionnaires which were subsequently analyzed. The women were within the ages of 15 to 44 years of age.

Ethical consideration: Ethical clearance was obtained from the Ethical Committee of the Jos University Teaching Hospital. Participation in the study was voluntary after due explanation of the purpose and objectives.

\section{Results}

The majority of the respondents (32\%) were females between the ages of 40-44years while $22 \%$ were aged between 25-29years of age. Of these, $51 \%$ were farmers while $31.9 \%$ were artisans. The rest were civil servants and students. A majority of the respondents $(73.1 \%)$ were Christians of the Protestant persuasion while $16.4 \%$ were Catholic and $7.2 \%$ were Pentecostals. Islam and Traditional religion adherents were $0.01 \%$. The predominant ethnic group among respondents was the Berom ethnic group which was $99.8 \%$ of the study population.

$80 \%$ of respondents preferred hospital delivery while $19 \%$ chose home delivery and $1 \%$ chose delivery with TBAs (Figure 1).

The mother's safety was the major determinant of the choice of place of delivery by $1,927(73 \%)$ of the respondents, the cost of services was the next determinant in $633(24 \%)$ of the respondents while the attitude of the health care providers at hospitals was the least consideration in $79(3 \%)$ of the respondents for the choice of place of delivery. There was no significant relationship between choice of place of delivery and educational status p 0.430. (Table 1). There was also no significant relationship between the age ranges and choices made for place of delivery $\mathrm{p}=0.455($ Table 2$)$. 


\section{PREFERRED PLACE OF DELIVERY}

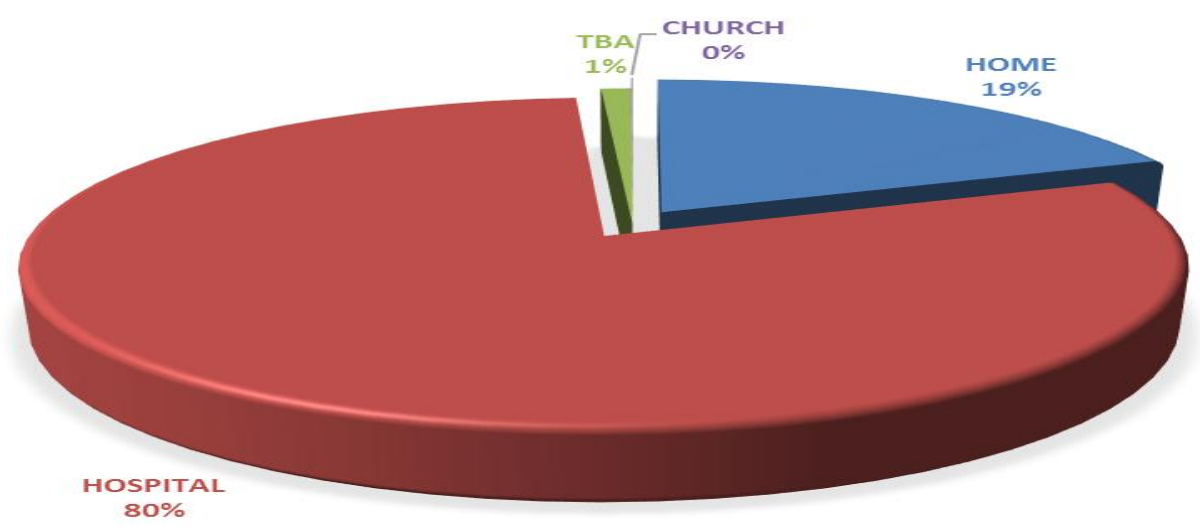

Figure 1

DETERMINANTS OF PLACE OF DELIVERY

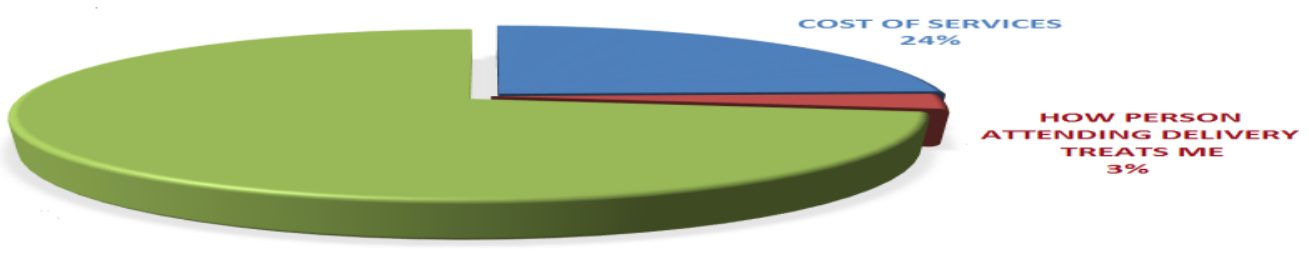

Figure 2

Table 1 Education and Preferred Place of Delivery

Count

\begin{tabular}{lllllll}
\hline \hline & & \multicolumn{2}{l}{ Which is your Preferred Place of Delivery } & \\
\cline { 3 - 6 } & & Home & Hospital & TBA & Church & Total \\
\hline Education & Primary & 239 & 979 & 10 & 0 & 1228 \\
& Secondary & 140 & 542 & 7 & 0 & 689 \\
& Tertiary & 26 & 159 & 3 & 0 & 1 \\
& No Formal Education & 103 & 425 & 6 & 1 & 535 \\
\multirow{2}{*}{ Total } & 508 & 2105 & 26 & 2640 \\
\hline \hline
\end{tabular}

$\mathrm{X}^{2}=\mathbf{9 . 0 8 3}$ p 0.430 
Table 2 Age Range and Preferred Place of Delivery

\begin{tabular}{|c|c|c|c|c|c|c|}
\hline & & \multicolumn{4}{|c|}{ Preferred Place of Delivery } & \multirow[b]{2}{*}{ Total } \\
\hline & & Home & Hospital & TBA & Church & \\
\hline \multirow[t]{6}{*}{ Age } & $15-19$ & 2 & 25 & 0 & 0 & 27 \\
\hline & $20-24$ & 38 & 209 & 1 & 0 & 248 \\
\hline & $25-29$ & 119 & 458 & 4 & 0 & 581 \\
\hline & $30-34$ & 100 & 377 & 5 & 1 & 483 \\
\hline & $35-39$ & 81 & 373 & 7 & 0 & 461 \\
\hline & $40-44$ & 168 & 663 & 9 & 0 & 840 \\
\hline Total & & 508 & 2105 & 26 & 1 & 2640 \\
\hline
\end{tabular}

$X^{2}=14.957 p=0.455$

\section{Discussion}

This study showed that the mother's safety was the major determinant of the choice of place of delivery in $73 \%$ of the respondents, the cost of services was the next determinant in $24 \%$ while the attitude of the health care providers at hospitals was the least consideration in $3 \%$ of the respondents for the choice of place of delivery. There was no significant relationship between educational status and choice of place of delivery $\mathrm{p}$ value 0.430 . There was also no significant relationship between the age ranges of the respondents and the choices for place of delivery $p=0.455$. The majority of respondents also opted for hospital delivery.

Delivery assistance by a skilled provider is a critical factor in improving maternal mortality ratio yet a large number of Nigerian women prefer to deliver at home. ${ }^{8}$ The findings in this study however showed that most women $(80 \%)$ within the reproductive age in the community surveyed preferred to deliver in a hospital because their main concern was the safety of the mother/baby (73\%). This contrasts with findings in a similar study by Envuladu in Jos albeit in a smaller sample in an urban setting in Russia village of Jos who preferred to deliver at home. ${ }^{10}$

The reasons given for the preference for home delivery in the Envuladu study among others was the unfriendly attitude of health workers in hospitals and the cost of care. In our study, cost and attitude of health care workers were an influencing factor for the place of delivery in $24 \%$ and $3 \%$ of respondents respectively. In this study, all women in the reproductive age group irrespective of pregnancy status were surveyed as against only pregnant women in the Envuladu study. A similar study in Zaria carried out in a semi urban area, also showed high rates of home deliveries $(70 \%)$ and deliveries not supervised by skilled attendants $(78 \%)$ respectively. ${ }^{11}$ Most of the respondents in this study had primary and secondary education as their highest educational attainment. 979(37\%) of those with primary education said they would deliver in hospitals while 239(9\%) said they would opt for home deliveries. Among those that had secondary education as their highest educational attainment, $542(21 \%)$ said they would opt for hospital deliveries and 5\% responded that they would prefer home deliveries. Other studies have found lower educational status to be one of the factors associated with home deliveries along with low income, increased maternal age and being divorced or separated at the time of delivery. ${ }^{12,13}$ Our study did not show the level of education to influence choices of place of delivery.

Another community based study by Ejembi in Zaria, Northern Nigeria demonstrated that skilled birth attendants were present in only $7 \%$ of case in $95 \%$ of women who had home deliveries. ${ }^{14}$ Similar findings have been demonstrated in studies done in SouthWestern Nigeria. ${ }^{15}$ It is therefore heartening that women in the surveyed community chose the safety of the mother as the most important consideration when deciding on where to deliver and chose hospitals as their preferred place of delivery even 
though the level of health care provided in the hospitals they would choose could not be determined by the tool we used.

The finding in this study that the attitude of the health care workers was the least consideration that influenced delivery intentions contrasts with a study in the South-South of Nigeria where the harsh attitude of health care workers in hospitals accounted for $12.1 \%$ of women opting to deliver in prayer houses. $^{16}$

The finding in our study was that there was no significant difference in choices made by the respondents on the place of delivery based on their educational status or age groups .This contrasts with similar studies in South East Nigeria and Ethiopia where the ages of women and their educational status were predictors of places they chose to deliver their babies. $^{17,18}$ This we attribute to previous public enlightenment campaigns carried out across different age groups in the population.

These other studies however differed from ours because they interviewed pregnant women while only women in their reproductive age irrespective of their pregnancy status or past obstetric experiences were surveyed in this study.

\section{References}

1. Trends in Maternal Mortality: 1990 to 2013; Estimates by WHO, UNICEF, UNFPA, The World Bank and the United Nations population Division. Geneva World Health Organization 2014.

2. Tukur J, Jido TA, Awolaja BS. Maternal mortality in rural Northern Nigeria.TropDoct 2008; 38:35-36.

3. Olatunji AO, Sule-Odu AO. Maternal mortality at Sagamu, Nigeria- A ten year review (1988-1997) Niger Postgrad Med J 2001;8:12-15.

4. WHO. World Health report 2005; Make every mother count. Geneva 2005.

5. 2013 Nigeria Demographic and Health Survey. Available at : https://www.unicef.org Accessed 14th September 2017

6. BabalolaS,Fatusi A. Determinants of use of maternal health services in Nigeria- Looking beyond individual and household
A limitation in this study is that the majority of the respondents in this study were farmers and of the Christian faith, being largely homogenous, comparisons could not be made between other occupations or other religious groups because they were of very small numbers. We were also unable to assess the average earnings of the respondents or their spouses as most of them were unable to make such estimates. This hindered us from analyzing the important variable of finances as a determinant of place of delivery.

This study aimed at knowing the intentions, and not the actual place of delivery, conclusions on actual place of delivery during labor could change. As a follow up, it will be of interest to know where the respondents actually deliver when they are in labor.

\section{Conclusion}

A majority of the respondents in this study opted to have hospital deliveries; this is a positive health seeking attitude that should reduce maternal and neonatal morbidity and mortality in the district. This has positive implications for health service delivery and reproductive health in this population.

factors.BMC Pregnancy Childbirth 2009;9:43.

7. Lawoyin TO. Onadeko MO, AsekunOlarimoye EO. Neonatal Mortality and perinatal risk factors in rural southwestern Nigeria: A community based perspective. West Afr J Med. 2010; 29: 19-23.

8. Udo JJ, Anah MU,Ochigbo SO, Etuk IS, Ekanem AD. Neonatal morbidity and mortality in Calabar, Nigeria: A hospital based study. Niger J ClinPract.2008; 11: 285-289.

9. Reproductive Health resource survey at primary health care level of government facilities; FMOH; Abuja; 2002.

10. Envuladu EA, Agbo HA, Lassa S, Kigbu JH, Zoakah AI. Factors determining the choice of a place of delivery among pregnant women in Russia village of Jos North, Nigeria: Achieving the MDGs 4 and 5.Int J Med Biomed Res 2013; 2(1):23-27.

11. Idris SH, Gwarzo UMD, Shehu AU. Determinants of Place of Delivery among 
Women in a Semi Urban Settlement in Zaria, Northern Nigeria. Ann Afri Med.2006; 6:6872.

12. Katung PY. Socioeconomic factors responsible for poor utilization of primary health care services in a rural community in Nigeria. Nig J Med 2001; 10: 20-59.

13. Ikeako L.C,Onah H.E, Iloabachie G.C. Influence of formal maternal education on the use of maternity services in Enugu, Nigeria. $\mathrm{J}$ ObstetGynaecol 2006; 26: 30-34.

14. PrataEjembi C, Fraser A. Shittu O, Minkler M. 2012. Community mobilization to reduce postpartum haemorrhage in home births in northern Nigeria. SocSci Med, 74: 1288-1296.

15. Olusanya BO, Wirz SI, Luxon LM. 2008. Non Hospital delivery and permanent congenital and early onset hearing lose in a developing country. BJOG 115: 1419-1427.

16. Udoma EJ, Ekanem AD, Abasiattai AM, Bassey EA. Reasons for preference of delivery in spiritual church based clinics by women of South south Nigeria .Niger J ClinPract2008; 11.100- 103.

17. Egharevba J, Pharr J, van Wyk B, Ezeanolue E. Factors Influencing the choice of child delivery location among women attending antenatal care services and Immunization clinic in South Eastern Nigeria. Int J MCH AIDS 2017; 6(1) : 82-92.

18. Yegezu RT, Kitila SB. Assessment of factors affecting choice of delivery place among pregnant women in Jimma Zone, Southwest Ethiopia. Cross sectional study. J Women's Health Care 4:211. doi:10.4172/21670420.1000211 